\title{
UNIVERSITYOF
}

FORWARD

THINKING

WESTMINSTER用

WestminsterResearch

http://www.westminster.ac.uk/westminsterresearch

Making sense of the evolving nature of depression narratives and their inherent conflicts

Ridge, Damien T.

This is a post-peer-review, pre-copyedit version of an article published in Subjectivity.

The definitive publisher-authenticated version of Ridge, Damien T. (2018) Making sense of the evolving nature of depression narratives and their inherent conflicts, Subjectivity, 11 (2). is available online at:

https://dx.doi.org/10.1057/s41286-018-0048-z

The WestminsterResearch online digital archive at the University of Westminster aims to make the research output of the University available to a wider audience. Copyright and Moral Rights remain with the authors and/or copyright owners.

Whilst further distribution of specific materials from within this archive is forbidden, you may freely distribute the URL of WestminsterResearch: ((http://westminsterresearch.wmin.ac.uk/)).

In case of abuse or copyright appearing without permission e-mail repository@westminster.ac.uk 


\section{Making sense of the evolving nature of depression narratives and their inherent conflicts}

\section{Abstract}

Originally a psychiatric diagnosis fashioned by Western psychiatry in the $20^{\text {th }}$ Century, depression evolved to encompass varying lineages of discourse and care. This article elucidates some of the current challenges - as well as emerging discourses - influencing the category of depression. Depression-like experiences are shaped by (at times conflicting) subjectivities, claims to knowledge, material realities, social contexts and access to resources. With no unified understanding of the category of 'depression' available, lay people, social and neuro scientists, GPS, psychiatrists, talking therapists and pharmaceutical companies all attempt to shape narratives of depression. The current paper focuses on patient narratives about depression - in the context of these wider debates - to better elucidate the ways in which depression discourses are publically developing along varying lines. In conclusion, the paper suggests that we could better conceptualise the resulting 'depression(s)' with concepts such as 'society of mind' and notions of subjectivity unbounded by individuals.

Key words: Depression, narrative, patient experience, psychiatry

Acknowledgements: I would like to thank Alex Broom and Volker Scheid, discussions and exchanges with whom helped to shape the original paper, along with Renata Kokanovic and the organisers of the excellent Broken Narratives and the Lived Body conference held at the Monash Prato Centre in Italy in 2016, where this paper was first presented. The feedback from the anonymous reviewers was 
valuable in further developing the arguments in the paper, and critical readings of the manuscript by Petra Makela and Alison Fixsen helped to clarify the final paper.

\section{Introduction}

A dominant paradigm in psychiatry is that discoveries are made in the basic sciences, and then flow through to inform practice and applied research (Priebe, Burns and Craig 2013). Here, genetics and neurobiology are assumed to explain mental illness, rather than contribute to our understanding of complex mental conditions. Western psychiatry has been powerful in shaping mental illness constructions. However, from the second half of the $20^{\text {th }}$ Century the focus on diagnoses and the role of biology meant that a deeper understanding of patient subjectivities and contexts (and the implications for alleviating suffering) has not always been high on the agenda (Cooksey and Brown 1998). Despite the ascendency of biological explanations for depression (Lebowitz and Ahn 2015), new pharmaceutical treatment advances have stalled in the modern era, while the "evidence of the importance of personal relationships in shaping both cause and cure" (p. 320) of mental conditions has continued to accumulate (Priebe, Burns and Craig 2013). Critical social scientists have long argued that it is only through focusing on subjectivities, social relations and contexts (e.g. childhood attachments, trauma, poverty, gender relations), and not just neuroscience and genetics, that the formation, texture and experience (and amelioration) of mental health problems could be better understood (Cooper 2004; Pilgrim, Rogers and Bentall 2009; Rogers and Pilgrim 2014). In the area of depression, the National Institute for Health \& Care Excellence (NICE) in England has highlighted the importance of meaning-making research, noting that a "wide range of biological, psychological and social factors, 
which are not captured well by current diagnostic systems, have a significant impact on the course of depression and the response to treatment' (p. 6) (NICE 2009). As diagnosis is not a reliable guide to treatment, the requirement for psychiatric nosologies to better encompass complex interactions of genetics, neuroscience, and wider psycho-social issues has been emphasised (Cuthbert and Insel 2013).

While critical social scientists note that too much emphasis has been placed on diagnosis and biology, we are yet to develop alternative narratives about depression that could capture the public imagination in the way that the 'chemical imbalance' hypothesis continues to. There are striking candidates for better stories; it is known, for instance, that the brain maintains neuroplasticity into adulthood, that psychotherapy can lead to neural changes, and the environment itself influences genetic expression (Lebowitz and Ahn 2015). This narrative of 'multi-directional traffic' between the biological and the social has the potential to challenge the imbalance story. Applied to diagnoses like schizophrenia, for example, the issues include ongoing questions about the coherency of the diagnosis and inconclusiveness about biological bases. Here, there are endeavours to find alternative ways of framing the problem, such as by focusing biopsychosocial investigations on homogenous experiences like voice hearing instead of complex psychiatric constructions (Cromby 2016), or the ways in which trauma (a history of childhood abuse specifically) can powerfully shape biology and social experiences (Janssen et al. 2004). The newer multi-directional understanding of mental health has compelled scholars to plead for greater balance in the face of the "increasing dominance of a biological approach to mental health problems" (p. S460) (Kinderman, Pini and Wooley 2017). 


\section{Approach to analysis}

In this paper, the argument put forward is for an approach to depression that better contends with the (frequently) competing claims made about this particular kind of distress. The paper's analysis is situated in debates about depression in the wider literature. In particular, it draws on patient narratives of depression collected and analysed via a number of studies that were conducted using the scholarly methods developed by the Health Experience Research Group (HERG) at Oxford University (Ziebland \& Hunt 2014). Participants were all recruited into studies either via health practitioners and other networks (e.g. mental health charities). Each study aimed to capture a wide range of variation in experiences (e.g. treatment approaches, severity of depression) and socio-demographics (e.g. gender, age, ethnicity). Participants' ages ranged between 18 and 84 years, all but a few of whom had been diagnosed with depression by a medical doctor and/or had been prescribed antidepressants. Most interviews were conducted with people at the more severe end of depression, and included participants with multiple episodes over their lifetimes, many times requiring hospital admission. Interviews were mainly conducted in people's own homes, although venues could also include workplaces, universities, library rooms and hotels. Participant depression narratives were retrospective in that people were not suffering from debilitating depression at the time of interview. Participants were initially asked about their experiences of living with depression and/or using antidepressants via interviews that elicited personal narratives as a way of providing rich data (Hollway and Jefferson 1997), beginning before depression onset/antidepressant use through to the current day. Additional questions relevant to the study were also asked at the end of the interview if not already covered, for 
example about recovery. Interviews averaged around 2 hours in length. All interviews were conducted by experienced researchers, were recorded, transcribed verbatim by professional transcribers, and returned to participants for checking, correction and comment. The approach to analysis was thematic in nature (Braun and Clarke 2006), using constant comparison techniques to ensure rigour (Dye et al. 2000), and incorporating concepts from the literature to help develop and clarify analyses, i.e. a modified constant comparison approach (Lomas et al. 2013).

\section{Biology and widening constructions of depression}

Stories about biologically determined depression are presented to the public with ever greater conviction. At the time of writing this paper, the immune system is being presented as a new potential culprit for depression (Gallagher, Buchanan and LuckBaker 2016). While the public are encouraged to share in this 'cutting edge science' (p. 109) (e.g. via the British Broadcasting Corporation (BBC)), dissenting views are conspicuous by their absence (Morgan 2017). One idea put forward by the proponents of the immune hypothesis is that inflammatory chemicals enter the brain from the body and cause depression, perhaps by interfering with serotonin levels (Mclnnes 2014). A problem with this story is that the serotonin deficiency causal hypothesis for depression has a significant credibility problem, as outlined below. Nevertheless, the inflammation argument breathes new life to an old chemical imbalance story, while reconfiguring the body and subjectivity in new ways. Consider also that a causal link between endogenous opiates and depression has been hypothesised, on the basis that people with depression can 'feel better' when taking opiates (Fava et al. 2016). However, as the current paper (and others) argue (for example, see Trivelli (2014)), biology, personal narratives, and political contexts 
converge to create depression stories that are nevertheless signified by their real world consequences, even if they remain somewhat elusive and disparate. If we allow the story about biological determinism to unfairly dominate the field, then so too do we promote a level of pessimism about the prospect of gaining personal mastery over depression, a biologically determined condition in need of a pharmaceutical fix, not social interventions (Lebowitz \& Ahn, 2017).

The Diagnostic and Statistical Manual of Mental Disorders (DSM) of the American Psychiatric Association (APA) has been widely used by psychiatrists to diagnose depression since the second half of the $20^{\text {th }}$ Century. The manual was (and remains) a shifting political as much as scientific document, fashioned out of the defeat of psychoanalysis by bio-psychiatry in the mid 20 $20^{\text {th }}$ Century (McPherson and Armstrong 2006; Pilgrim 2007). Earlier notions of melancholia were opaque and not a close match for depression; not that is, until the $19^{\text {th }}$ Century, when melancholia moved closer to our modern understanding of mood disorders (Berrios 1988). From the 1950 s onwards, various ways of classifying depression (e.g. once called 'endogenous' and 'reactive' depressions, then 'major' and 'minor' depression from the early 1980s), proliferated in medical journal citations, influenced by categories made available in successive editions of the DSM (McPherson and Armstrong 2006). It was, however, major depression that captured the $20^{\text {th }}$ Century mood, becoming a highly successful franchise for the APA (not to mention for the pharmaceutical industry that historically was at pains to nurture close links to the scientific panel responsible for developing the DSM) (Cosgrove et al. 2006). So much so, that by 2012, the World Health Organization announced that depression had become the 
leading cause of disability worldwide, affecting 350 million people at any one time (WHO 2012).

However, if depression is socially produced, and dependent on forms of power and influence as argued above, then it is useful for us to focus our attention on the real world laboratory, involving claims and counter-claims about depression by patients, scientists, health professionals, the pharmaceutical industry and so on (Latour 2004; Priebe, Burns and Craig 2013). Depression screening or diagnosis involves clinicians considering a descriptive list of symptoms (e.g. low mood, loss of interest) to ensure the right - and sufficient numbers of - symptoms are present for enough time, while ruling out other diagnoses (Kessler et al. 1996). This apparently systematic approach covers over some peculiarities about depression. One issue is that no one can say with any authority what depression actually is (nor other mental health diagnoses for that matter); neither those that experience it, nor those that investigate it (Trivelli 2014). One cognitive neuroscientist (well known for) investigating neuro-psycho-pharmacological underpinnings of depression and anxiety (Oliver Robinson) put it this way, "I literally have no idea [what depression is]" (online) (Shariatmadari 2015).

Another key issue with depression is that lay people now actively deploy depression discourses in ways that psychiatry could not have anticipated in the $20^{\text {th }}$ Century (McPherson and Armstrong 2009). Less than half of the 350 million people who experience depression globally receive treatment (WHO 2012); many go undiagnosed, or self-diagnose (e.g. via the Internet) (Ryan and Wilson 2008). Not surprisingly then, people are adept at appropriating depression discourses (Epstein 
et al. 2010). One study, for example, found that people can deploy the language of depression as a "precise kind of political affect" (p. 333), experienced in circumstances of austerity and the production of workers for the needs of capitalism (Stern and Brown 2016). Here, participants must work out how to self-medicate and/or find meaning out of situations that generally inspire hopelessness. Alternatively, depression can become a repository for all the difficult emotions that society says are not acceptable and should be remedied (Dowrick and Frances 2013). Not surprisingly, these generative, multiple threads of depression(s) are inadequately captured and dealt with by authorities. In terms of treatment, antidepressant prescription (the main treatment for depression) without any other ongoing personal support, can easily spawn patients who resist authority (Anderson et al. 2015). Or as 27-year-old Nicole put it, "I think taking medication is something I really struggled with because I didn't want to take it. I didn't want to-you know, I thought I could just get better on my own." Thus, attempts to medically delineate and treat depression are inevitably doomed to perpetual challenge, if not failure.

In many cases the medical profession themselves frequently assist patients diagnosed with depression to develop alternative stories about their condition. For example, many general practitioners (GPs) work to de-medicalise the stories presented by their patients, instead promoting notions of the condition as only knowable in social context (Kokanovic et al. 2010), e.g. as a signifier for life's hidden problems and inequalities their patients must face (Körner et al. 2011). For 'difficult' patients, doctors may de-medicalise the condition in other ways, such as drawing on lay ideas of social deviance to signify patients they experience as particularly unpleasant (McPherson and Armstrong 2009). The condition can be taken in other 
non-DSM directions too. Psychoanalysts, for example, frequently construct depression as a defence against less conscious thoughts and feelings that threaten to overwhelm the individual, either interpersonal (e.g. due to feelings of abandonment) or via a punishing internal self-critic (as voices internalised from past harsh authority figures) (Blatt 1998).

Questions can also be raised about depression as a Westernised construct. In some parts of China, for example, concepts of depression and emotions are resisted, and depression-like experiences are apprehended through the lived body, as a discomfort, an inner pressure or bodily pain, rather than psychologically (Kleinman and Good 1985). However, a close reading of patient accounts of depression in the West shows the condition is embodied in interesting ways here too (Ridge 2009). For one male participant, the onset of depression was described as, "I have this sort of pressure around my brain, you know I feel that someone's got their hands inside there." While for another, depression was heralded by a change in her voice, among other wide-ranging physical manifestations: “... I can’t sing any more, I love singing to music in the car or in the kitchen. My... you can hear from my voice, it completely changes. I think my, also my posture changes I think, I suspect. And I can't describe the physical changes. They, they, it's as if, you know, there's a whole sweeping change inside my body. It's very difficult to describe what it is. The most noticeable is my voice." Some of these somatic accounts read more like a bodily change, invasion, or possession (a belief system common in some societies, including parts of China (Kua, Chew and Ko 1993)), with the symptoms of depression as outlined in the DSM underplayed in such accounts. 
Understanding the different ways in which depression-like experiences are narrated is key to assisting the broadest range of people to recover (Ridge and Ziebland 2006). While reification of depression as a disease entity(ies) helps some people (e.g. by giving a label for their condition), others find this approach less helpful, or may not think about their depression-like issues in mental health terms at all, but rather as "struggling with life" (p. 204) (Lomas et al. 2013). What most participants in our studies seem to have in common though is the ability to piece together a more or less useful story about their experiences in retrospect, frequently characterized (at least initially) by halting narratives, lack of vocabulary, disconnected feelings, problems with self-knowing, and perplexing bodily sensations (Ridge 2009). Veronica, for example, described how she found herself alarmingly cut off from herself and her family, where she could only remember that she loved them and was loved herself: "I couldn't feel anything at all. My emotions were completely dead. And I was just very frightened."

In examining so called 'depression', there are limitations introduced by creating a binary with the biological by splitting the body off, or limiting ourselves to DSM descriptions, or professional constructions available in the UK's publically funded 'National Health Service' (NHS). Antidepressants are a case in point. Antidepressants, whose legitimacy is questioned by a wide variety of patients as indicated above (Anderson et al. 2015), not to mention scholars (Buus 2014), are nevertheless are increasingly popular medical prescriptions (Spence et al. 2014). Additionally, they are reported by our participants to generate traffic between biology and subjectivity. Thus, counter-narratives are possible, whereby some users challenge folklore about antidepressants creating 'fake' selves and feelings. The 
counter claims are that the medication allows people to get in touch with their authenticity (e.g. "Sertraline [is] a bit like Berocca, it's you on a good day"), or helps people get to the heart of the problem causing their depression (Ridge et al. 2015), e.g. "the tablets have helped the sort of underlying cause that has allowed me to embrace the CBT [Cognitive Behavioural Therapy]." Thus, subjectivity can usefully be re-worked biochemically in this view (Fraser 2001).

\section{Bad Chemistry: Chemical imbalance narratives}

Persistent ideas that antidepressants correct chemical imbalances need to be challenged (Middleton and Moncrieff 2011), and it should be noted from the outset that the claimed efficacy of antidepressants is disputed. Some work has showed that antidepressants do not have advantages over placebos (Moncrieff and Kirsch 2005). However, the placebo effect is known to be substantial in its own right (Foot and Ridge 2012), and antidepressants would need to be significantly better than the placebo effect for a positive randomised control trial $(\mathrm{RCT})$ result. Additionally, the privileging of RCTs is known to side-line other forms of evidence of patient benefit, including patient accounts (Victora, Habicht and Bryce 2004). On balance, more recent research has found that antidepressants do have an effect above and beyond the placebo effect in RCTs, but their benefits are limited (Cipriani et al. 2018; Kirsch et al. 2008).

One problem with common antidepressants (selective serotonin re-uptake inhibitors - SSRIs - specifically) is that the once frequent assertion that they help depression by correcting a chemical imbalance (specifically a lack of serotonin) never had specific support in the scientific literature (Lacasse and Leo 2005). This narrative, 
however, was a successful selling point for the pharmaceutical industry, capturing the public imagination as fact. The story also gave health professionals an easy way to explain antidepressants to patients, while promoting antidepressants as a logical (and relatively cheap) treatment for depression (Healy 2015). Mischievous researchers once asked journalists who had publically claimed that depression was caused by a chemical imbalance to provide evidence to back up their claims, which of course no one could do (Leo and Lacasse 2008). At the same time, the metaphor (once widely proclaimed) that taking antidepressants for depression was akin to taking insulin to correct for diabetes was increasingly questioned by both patients and their health professionals (McMullen and Sigurdson 2014). As mysteriously as it appeared, the chemical imbalance story was retired from public life. Pharmaceutical companies subsequently replaced their chemical imbalance stories with more evidence-based claims about the pharmaceuticals 'adjusting' neurotransmitters (Lacasse and Leo 2015).

Nevertheless, the chemical imbalance story had already resonated with the public, and was widely adopted to make sense of lives: Patients could not discard it as easily as the pharmaceutical industry. Nevertheless, there was a defiance and defensiveness surrounding the use of the story by patients. While not necessarily responding to such nuanced scientific debates as outlined above, Mathew's defiance underpins the extent to which he understands that the legitimacy of his beliefs is contested:

I mean it's [depression] chemical, you know I'm quite, you know I'm quite happy to admit there's something screwed up about my brain chemistry, you know. But you know, some people are diabetic, they take drugs, you know. 
And I know people say, "Oh, it's not the same." But I'm afraid it bloody well is! [Mathew]

As intimated above, the chemical imbalance story clashes with an optimistic (and another institutionalised) narrative about the possibility of recovering from depression: How can you recover from a chemical imbalance in your brain? Chemical imbalance narratives sit alongside more hopeful recovery narratives fashioned out of $20^{\text {th }}$ Century psychiatric deinstitutionalisation and the psychoactive pharmaceutical revolution (Braslow 2013). Recovery is commonly touted as being about "building a meaningful and satisfying life, as defined by the person themselves, whether or not there are ongoing or recurring symptoms or problems" (p. ii) (Shepherd, Boardman and Slade 2008). However, the recovery movement is not without its critics, and some argue that recovery moved away from personcentred definitions to become co-opted by health services and governments in ways that ended up disempowering patients (Gordon 2013). Davidson and colleagues (2005) for example, consider the professional take on recovery (e.g. alleviating symptoms and measuring outcomes) as being at odds with the agenda of patients, including the importance of consumer-led movements in challenging the status quo.

While unhelpful chemical imbalance stories about mental health have particular veracity, they can cancel out competing claims about depression. David, for example, casually dropped into his story a traumatic childhood experience which appeared particularly salient in explaining his later experiences of recurrent depression. However, he quickly disregarded his highly traumatic experience for a chemical imbalance story: 
And we got very nearly bombed... About two hundred yards from the bottom of the garden was an airfield, well the airfield that's still there, and the Germans came and dropped bombs that close. My brother and I witnessed an eighty-eight machine gunning the harvesters out in the field, the men were out, harvesting the crops with the horses and carts and a plane came along and machine gunned them... I think you get it (depression) or you don't, at some time your chemicals get mixed up and that's it. You get one, a lack of one chemical, and you get an imbalance and there it starts.

[David]

People who experience depression are frequently encouraged to close down deeper examination of (and not coincidently more emotionally difficult) issues underpinning their condition (Dowrick 2004). And the chemical imbalance narrative also means that people who feel that antidepressants 'complete them' may feel justified in staying on the medication permanently, even if the weight of evidence suggests that they might be better off discontinuing their medication (Kendrick 2015), a daunting prospect for many people. There are the embodied and psychological effects of 'discontinuation syndrome' (Tamam and Ozpoyraz 2002), which can be dramatic and highly alarming (for example, from our research, "....so every so often it's like you get an electric shock in your tongue, it was just awful. I had the shakes, I had dry mouth, it was just horrendous...). Additionally, people are many times very fearful of depression returning:

And so, I feel well, and for the next four and a half years from now I am quite safe. I can still continue taking that [antidepressants]. But in five years time, 
do I have to go back [to the GP] and sort of plead my case again? Ask as it were if I can continue taking them? Or do I have to go back through that misery of feeling that it's all going pear shaped again... [Liza]

Coming off long-term antidepressant use may also mean challenging the power of the chemical imbalance story. While research suggests that people are conflicted about the chemical imbalance narrative (Ridge 2009), the reality is that there is little by the way of health resources available in the UK to help people sort through the personal issues contributing to their depression and antidepressant use. According to the Chief Medical Officer, 3 in 4 people receive no treatment at all for their mental illness in England (Davis 2014). When treatment is sought and available, antidepressants are more convenient and cheaper than other forms of treatment (McCarthy 2013). However, the legitimacy - and morality - of antidepressant use is questioned by users themselves (not to mention the wider public). This is especially the case where people experience psychoactive, 'pseudo-illicit' effects from their medication, such as feeling high (Ridge et al. 2015), e.g. "Certainly with the amitriptyline I felt very much on a chemical high... buzzing round the ceiling." So powerful are moral concerns surrounding antidepressant use, even those who strongly argue against such interpretations must engage with illegitimacy narratives at some level. While there were many accounts of moral dilemma-free medication narratives, they were constructed in opposition to assumptions of illegitimacy, thus inadvertently reinforcing moral storylines. Thus, in trying to defend antidepressants, one participant ended up highlighting the clandestine nature of the medication and pseudo-illicitness (anonymous 2015): "Actually I just don't see any bad in them other 
than potentially the stigma... you don't have to share it with the world, you can do it yourself, it's a tiny little pill that you take and nobody ever needs to know about [it]."

\section{Re-writing depression narratives}

Instead of focusing on DSM endorsed symptoms (Lewis 1995), people attempt to make sense of their own personal experiences of depression, often using metaphors or ideas already available in the wider culture. Here, hellishness and feeling cut-off from others are very common accounts, e.g. "It is like rotting in the depths of hell", or "It was like being inside a very, very thick balloon and no matter how hard I pushed out, the momentum of the skin of the balloon would just push me back in." Navigating such difficult interior landscapes were key to coping with - and integrating - depressive experiences (Ridge 2009). Craig, for example, found that Vodka could temporarily lift him up and provide breathing space from the hellishness of his experience. For Pamela, her experience of depression was strongly accompanied with feeling like the black sheep of her family. It was only through a chance viewing of a documentary on dyslexia that she had the sudden realization that dyslexia was the key to her depression. Her feeling (with her 'clever' family reinforcing the idea) was that she was somehow inferior, and harsh self-reproach followed:

I firmly believe that my depression came from the dyslexia... The person that did the [dyslexia] assessment said, "You've actually got a very high IQ." And the joy of knowing that I had a problem, what my problem was, alongside the sorrow of all those missed opportunities... [Pamela]

Like Pamela quoted above, better dealing with depression variously involved gaining personal insights and telling a more useful story about themselves (e.g. dispensing 
with self-blame); adopting more hopeful 'recovery' attitudes (e.g. in the very depths of hell, one man felt joy because he knew at some point he would be lifted up); using 'recovery tools' (talking therapies were very commonly endorsed as useful); creating a space to experience and nurture personal insights; needing to engage with subjectivity 'authentically'; coming to terms with a 'false self' which frequently emerged in early life to cope with the agendas of others; and variously re-writing the story about depression as being less detrimental than previously understood (e.g. as a necessary wake-up call, a spiritual awakening) (Ridge and Ziebland 2006).

Our research also uncovered a new strand of depression discourse, where 'coming out' for those with depression (and as part of recovery) shared the language and tasks that sexual minorities have talked about following the advent of gay liberation (Ridge and Ziebland 2012). Similar to the stories of sexual minorities, stories about long-term and recurrent depression shared common milestones, including feeling vaguely different as a child; the need to accept or reject the label of depression; recasting depression as commonplace or advantageous (and not just as detrimental); needing to network with those who have had similar experiences; and contending with feelings of shame through to pride in terms of their depression; coming out of the depression 'closet' and even publically (sometimes militantly) challenging the stigma associated with depression, or as Ruth said, for example, “... explode it [stigma] whenever you can I say, but I've been very out because I've campaigned a lot on this...".

In another strand of depression storytelling, our analysis found that depression for men could be re-constructed in gendered terms, as involving a re-assertion of masculinity (Emslie et al. 2006), frequently by re-casting depression as a heroic 
battle (as opposed to a potentially feminizing condition). So one man described depression as an opponent, where he had to find a level of anger within himself to wrestle with this experience:

..,you've ...got to sort of reach down and... somehow find the strength deep down to start putting it into motion. It' s really weird. I got really, really angry at the depression... it was as if I was treating it as a person now... I just thought to myself 'No, you are just not going to do this to me. You know, you are not going to have this control that you've had over me for the last two years. .. I'm going to, you know, pull myself out of this'. [Patrick]

Less commonly, men challenged hegemonic masculinity in their re-telling of experiences of depression, for example, by highlighting the intrinsic value of their sensitivity and creativity (that might also predispose them to depression). As Paul put it, after a lifetime of experience with depression, “...I felt I was missing something. I didn't have something that the rest of the human race had. But in fact, it turned out almost to be the opposite. That in fact, you know we [with depression] have a certain sensitivity, I think."

A final strand of the depression narrative is silence. There is some evidence that psychodynamic or psychoanalytic approaches can help to alleviate depression (Driessen et al. 2010; Knekt et al. 2008). Here, the development of a constructive therapist-client relationship which allows a re-working of past relational injuries is thought to be important (Milton 2001). The hope in such therapy approaches is that the client internalizes the helpful functions of the therapist (e.g. a non-judgmental approach to the self as apposed to a self-critical inner voice) (Gabbard 2010). The 
most recent trial in the NHS showed that $44 \%$ of patients with treatment resistant depression, receiving long-term psychoanalytic psychotherapy (LTPP), could no longer be classified as having major depression at 2 years post-treatment follow-up (thus treatment benefits continued long after treatment stopped), compared with $10 \%$ of those patients receiving treatment as usual (Fonagy et al. 2015). Despite these encouraging findings, qualitative research into depression tends to fall silent just where the unconscious world of psychotherapy starts. Thus, where psychoanalysts might - through painstaking work with clients - conclude that an earlier formed fear of abandonment contributes to episodes of depression (and thus guides the treatment approach) (Blatt 1998), narrative research itself rarely (if ever) highlights abandonment as an explanatory framework for depression. Yet these less conscious, early experiences could help to shed light on amelioration of suffering (Cooper 2004; Pilgrim, Rogers and Bentall 2009). Certainly, our participants who were fortunate enough to access talking therapies were generally upbeat about their treatments, even if their access was limited to short-term courses. One participant who was fortunate enough to secure longer-term therapy - highlighted how complex the process of piecing together a narrative supporting her return from depression was:

It's like you can't sum it up in a sentence, what's the matter . . . you know. I've just spent a year in therapy and I still don't really . . . haven't got to the bottom of what's the matter with me. It takes time, you know. It takes discovery and it takes courage and it takes persistence and energy. [Belinda]

\section{Broken depression narratives}


Depression involves distinctive regimes and lineages of care in the UK, commonly involving no treatment, or antidepressant medication at best, or a waiting list for talking therapies for the fortunate (increasingly short-term cognitive behavioural therapy (CBT) is offered in the UK, through the Increasing Access to Psychological Therapies (IAPTs) programme on the NHS (Clark 2011)). Depression is also a term - and area of practice - that has been traditionally shaped by Western psychiatry. Yet, as outlined in this paper, depression is now interpreted via (sometimes incompatible) frameworks, on the part of lay people and different professionals. Our brief excursion through the varying constructions of depression suggests that people are actively coopting and pioneering different discourses as they recount depressionlike experiences. As the construction and contestation of depression continues to unfold, the most recent DSM (5 ${ }^{\text {th }}$ Edition) also met with controversy, for example, having been criticized for re-classifying grieving as potentially part of major depression (Wakefield and First 2012). This move by the APA was cited as an instance of unhelpfully medicalizing suffering through the expansion of a medical remit (Dowrick and Frances 2013).

Examining these kinds of instabilities and multiple, generative strands of narrative offer rich opportunities for us to re-think depression. From our brief exploration, patient and professional narratives tend to employ different rubrics to psychiatry classification systems, relying on metaphors to describe experiences that are difficult or impossible to otherwise articulate. Different kinds of patients and professionals tell different stories about the origins, qualities and potential treatments of depressions. Given this climate of diversity and disjuncture, and the relative lack of treatment availability (although many treatments have some evidence to support them), it is to 
be expected that lay people will self-diagnose and self-define/manage their depression (Ridge and Ziebland 2006). As argued above, a diagnosis of depression does not necessarily tell us all that much about the nature of the suffering. Nevertheless, a diagnosis of depression can be valued by patients for the way it affords a level of recognition:

... you can give someone tablets and [they] go away... And I think I could have benefited from that [depression] being recognised an awful lot earlier. I feel like I've almost lost twenty years of my life by that not being diagnosed. [Rosey]

This paper also explored some ambiguities in current qualitative research into depression. For example, there is some disconnection between ideas generated in psychotherapy with patients who experience depression, and those that emerge from social science research about patient experiences. Some privileged research participants who have had access to long-term therapy (but as one of our participants noted, she had to 'fight' to get it on the NHS), are able to articulate the ways in which they valued therapy. In reality, most patients in the UK will only have access to antidepressant medication, and perhaps CBT after a relatively long waiting time. Participants can be positive about CBT on the NHS, although not always (Ridge 2009). And while CBT is useful to many people and has an evidence-base, for other patients, it does not begin to reach their particular kind of suffering (Rizq 2012). Additionally, some research suggests that trials of $C B T$ for depression have revealed a steady decline in effectiveness from the original trials beginning in the late 70s (Johnsen and Friborg 2015), perhaps related to the expansion of services with less skilled practitioners than those originally trained in CBT. 


\section{Conclusion}

The current paper outlined how depression is being actively contructed along multiple, fragmented lines. At least initially, constructions of the category were heavily influenced by medical authorities. Today, however, there are increasing claims and counterclaims generated about depression and treatment, many of which are difficult to reconcile. For instance, this paper outlined how new discourses about depression emerge from the effects of neoliberal austerity policies, and the masculinised (re)construction of depression as a heroic journey rather than an especially feminised complaint. Nevertheless, there are interdisciplinary debates which can help shed light on varying depression constructions. Blackman (2014), for example, focuses on the way in which 'contagion' of ideas works in networks, arguing that hitherto neglected topics in science such as ‘suggestion' can help elucidate the affective processes going on in such areas. Blackman deployed the Derridian concept of 'hauntology' (as something erased yet still palpably present) to explore what could have been if Western psychological experimentation had retained its historical focus on "the processual, indeterminate, entangled technical-material affective agencies that cannot be reduced to psychological capacities relating to distinctly bounded human subjects." (p. 368) Thus, claims about the unconscious, transmission of ideas, and odd experiences sidelined in current depression discussions (e.g. changes in voice tone, or of a hand reaching into the brain, or of embodied changes in the body) could become more central to our investigations of depression.

Despite the apparent birth of depression via the $20^{\text {th }}$ Century DSM, the splintering and lack of connectedness - of ideas about depression remains the current state of 
play. Furthermore, it does not always seem useful to try and cobble together a coherent or definitive account of depression from these threads. Instead, there are apparent developments and assemblages of claims and ideas, and silences around other issues, that may be worth examining. According to Hermans (2013) it is possible to view the participants in such debates relationally, as 'dialogical selves' functioning "as a part whole; as a society of mind with tensions, conflicts, and oppositions ... The voices of other individuals, the collective voices of groups, and even the power games of societal institutions enter the self-space of the individual and challenge the self to give an answer. Along these lines, a self emerges in which different voices agree or disagree with each other, lead to unification or opposition, and are involved in relations of power and counter-power." (p. 149-150). Here, the claims to power, multiple voices and experiences are a product of relationships that extend back and forth between the bounded human subject, society, the unconscious and objects therein. Thus, for example, electroconvulsive therapy (ECT) for severe depression not only must consider issues of efficacy, but factor in lay memories about how health professional conduct themselves; the echoes of human traumas from the past, and the non-human artifacts (e.g. the experience of having the anaesthetic administered and other rituals surrounding the procedure) that powerfully shaped treatment recollections and perceptions of benefit (Knight et al. 2017). Resonating with memories and collective experiences, these human and non-human factors combined to determine whether ECT is experienced as a further trauma (e.g. "I've used the word 'abuse,' it [is] like another, but a mental abuse."), or alternatively, as a comforting (if not always effective) treatment (e.g. "[ECT is my] still point in a turning world"). Thus, as Blackman (2014) argues, the role of non-human 
agents, and the things we might have erased, can usefully be considered alongside the (frequently unbounded) forces that shape subjectivities. 


\section{References}

Anderson, C., S. Kirkpatrick, D. Ridge, R. Kokanovic, and C. Tanner. 2015.

Commencing antidepressant use: a qualitative synthesis of UK and Australian data. BMJ Open 5(12).

Berrios, G E. 1988. Melancholia and depression during the 19th century: a conceptual history. The British Journal of Psychiatry 153(3):298-304.

Blackman, L. 2014. Affect and automaticy: Towards an analytics of experimentation. Subjectivity 7(4):362-84.

Blatt, S.J. 1998. Contributions of Psychoanalysis To the Understanding and Treatment of Depression. Journal of the American Psychoanalytic Association $46(3): 723-52$

Braslow, J.T. 2013. The Manufacture of Recovery. Annual Review of Clinical Psychology 9(1):781-809.

Braun, V., and Clarke, V. 2006. Using thematic analysis in psychology. Qualitative Research in Psychology 3(2):77-101.

Buus, N. 2014. Adherence to anti-depressant medication: A medicine-taking career. Social Science \& Medicine 123(0):105-13.

Cipriani, A., Furukawa, T., Salanti, G., Chaimani, A., Atkinson, L., Ogawa, Y. et al. 2018. Comparative efficacy and acceptability of 21 antidepressant drugs for the acute treatment of adults with major depressive disorder: a systematic review and network meta-analysis. The Lancet 391(10128):1357-66.

Clark, D.M. 2011. Implementing NICE guidelines for the psychological treatment of depression and anxiety disorders: The IAPT experience. International Review of Psychiatry 23(4):318-27. 
Cooksey, E.C., and Brown, P. 1998. Spinning on its Axes: DSM and the Social Construction of Psychiatric Diagnosis. International Journal of Health Services 28(3):525-54.

Cooper, M. 2004. Towards a relationally-orientated approach to therapy: empirical support and analysis. British Journal of Guidance \& Counselling 32(4):451-60.

Cosgrove, L., Krimsky, S., Vijayaraghavan, M., and Schneider, L. 2006. Financial ties between DSM-IV panel members and the pharmaceutical industry. Psychotherapy and Psychosomatics 75(3):154-60.

Cromby, J. 2016. Developing schizophrenia. Theory \& Psychology 26(5):607-19. Cuthbert, B.N., and Insel, T. 2013. Toward the future of psychiatric diagnosis: the seven pillars of RDoC. BMC Medicine 11(1):126.

Davidson, L., O'Connell, M., Tondora, J., Lawless, M., and Evans, A. 2005. Recovery in Serious Mental Illness: A New Wine or Just a New Bottle? Professional Psychology: Research and Practice 36(5):480-87.

Davis, S.C. 2014. Annual Report of the Chief Medical Officer 2013: Public Mental Health Priorities-Investing in the Evidence. London: Department of Health.

Dowrick, C. 2004. Beyond depression: a new approach to understanding and management. . Oxford: Oxford University Press.

Dowrick, C., and Frances, A. 2013. Medicalising unhappiness: new classification of depression risks more patients being put on drug treatment from which they will not benefit. BMJ 347.

Driessen, E., Pim Cuijpers, P., de Maat, S., Abbass, A., de Jonghe, F., and Dekker, J. 2010. The efficacy of short-term psychodynamic psychotherapy for depression: a meta-analysis. Clinical Psychology Review 30(1):25-36. 
Dye, J.F, Schatz, I., Rosenberg, B., and Coleman, S. 2000. Constant comparison method: A kaleidoscope of data. The Qualitative Report 4(1):1-10.

Emslie, C., Ridge, D., Ziebland, S., and Hunt, K. 2006. Men's accounts of depression: reconstructing or resisting hegemonic masculinity? Social Science \& Medicine 62:2246 - 57.

Epstein, R.M., Duberstein, P.R., Feldman, M.D., Rochlen, A.B., Bell, R.A., et al. 2010. "I Didn't Know What Was Wrong:" How People With Undiagnosed Depression Recognize, Name and Explain Their Distress. Journal of General Internal Medicine 25(9):954-61.

Fava, Maurizio, Asli Memisoglu, Michael E. Thase, J. Alexander Bodkin, Madhukar H. Trivedi, Marc de Somer, Yangchun Du, Richard Leigh-Pemberton, Lauren DiPetrillo, Bernard Silverman, and Elliot Ehrich. 2016. Opioid Modulation With Buprenorphine/ Samidorphan as Adjunctive Treatment for Inadequate Response to Antidepressants: A Randomized Double-Blind PlaceboControlled Trial. American Journal of Psychiatry 173(5):499-508.

Fonagy, P., Rost, F., Carlyle, J.A., McPherson, S., Thomas, R., et al. 2015. Pragmatic randomized controlled trial of long $₫$ term psychoanalytic psychotherapy for treatment $\square$ resistant depression: the Tavistock Adult Depression Study (TADS). World Psychiatry 14(3):312-21.

Foot, D., and Ridge, D. 2012. Constructing the placebo effect in the placebo wars: What is the way ahead? Health Sociology Review 21(3):355-68.

Fraser, M. 2001. The nature of Prozac. History of the Human Sciences 14(3):56-84. Gabbard, G.O. 2010. Long-term psychodynamic psychotherapy: A basic text. Arlington, VA: American Psychiatric Publications. 
Gallagher, J., Buchanan, R., and Luck-Baker, A. 2016. Depression: A revolution in treatment? in BBC News. London: BBC.

Gordon, S.E. 2013. Recovery Constructs and the Continued Debate That Limits Consumer Recovery. Psychiatric Services 64(3):270-71.

Healy, D. 2015. Serotonin and depression. British Medical Journal 350:h1771.

Hermans, H. 2013. The Dialogical Self in Education. Journal of Constructivist Psychology 26(2):81-89.

Hollway, W., and Jefferson, T. 1997. Eliciting Narrative Through the In-Depth Interview. Qualitative Inquiry 3(1):53-70.

Janssen, I., Krabbendam, L., Bak, M., Hanssen, M., Vollebergh, W., de Graaf, R. and van Os, J. 2004. Childhood abuse as a risk factor for psychotic experiences. Acta Psychiatrica Scandinavica 109(1):38-45.

Johnsen, T.J. and Friborg, O. 2015. The effects of cognitive behavioral therapy as an anti-depressive treatment is falling: A meta-analysis. Psychological bulletin 141(4):747-68.

Kendrick, T. 2015. Long-term antidepressant treatment: time for a review? Prescriber 26(19):7-10.

Kessler, R.C., Nelson, C.B., McGonagle, K.A., Liu, J. et al. 1996. Comorbidity of DSM-III—R major depressive disorder in the general population: Results from the US National Comorbidity Survey. The British Journal of Psychiatry 168(Suppl 30):17-30.

Kinderman, P., Pini, P. and Wooley, S. 2017. Mental Health Europe's "Beyond the Bio-medical Paradigm Task Gorce" issues on ICD-10. European Psychiatry 41(Supplement):S460. 
Kirsch, I., Deacon, B.J., Huedo-Medina, T.B., Scoboria, A., Moore, T.J. and Johnson, B.T. 2008. Initial Severity and Antidepressant Benefits: A Meta-Analysis of Data Submitted to the Food and Drug Administration. PLoS Medicine 5(2):e45.

Kleinman, A. and Good, B. 1985. Culture and depression: Studies in the anthropology and cross-cultural psychiatry of affect and disorder. Berkley: University of California Press.

Knekt, P., Lindfors, O., Härkänen, T., Välikoski, M., Virtala, E. et al.. 2008.

Randomized trial on the effectiveness of long-and short-term psychodynamic psychotherapy and solution-focused therapy on psychiatric symptoms during a 3-year follow-up. Psychological Medicine 38(05):689-703.

Knight, F., Ridge, D., McShane, R., Ryan, S. and Griffith, L. 2017. Care, Control, and the Electroconvulsive Therapy Ritual: Making Sense of Polarized Patient Narratives. Qualitative Health Research 27(11):1675-85.

Kokanovic, R., May, C., Dowrick, C., Furler, J., Newton, D. and Gunn, J. 2010. Negotiating distress between East Timorese and Vietnamese migrants in Melbourne and their family doctors. Sociology of Health \& Illness 32(4):51127.

Körner, H., Newman, C.E., Mao, L., Kidd, M.R., Saltman, D.C. and Kippax, S. 2011. Discourses of Depression of Australian General Practitioners Working With Gay Men. Qualitative Health Research 21(8):1051-64.

Kua, E. H., Chew, P.H. and Ko., S.M. 1993. Spirit possession and healing among Chinese psychiatric patients. Acta Psychiatrica Scandinavica 88(6):447-50. Lacasse, J.R, and Leo, J. 2005. Serotonin and depression: A disconnect between the advertisements and the scientific literature. PLoS Med 2(12):e392. 
-. 2015. Antidepressants and the chemical imbalance theory of depression: A reflection and update on the discourse. The Behavior Therapist 38(7):206-13.

Latour, B. 2004. How to Talk About the Body? the Normative Dimension of Science Studies. Body \& Society 10(2-3):205-29.

Lebowitz, M.S. and Ahn, W. 2015. Emphasizing malleability in the biology of depression: Durable effects on perceived agency and prognostic pessimism. Behaviour Research and Therapy 71(Supplement C):125-30.

Leo, J. and Lacasse, J.R. 2008. The Media and the Chemical Imbalance Theory of Depression. Society 45(1):35-45.

Lewis, S.E. 1995. A search for meaning: Making sense of depression. Journal of Mental Health 4(4):369-82.

Lomas, T., Cartwright, T., Edginton, T. and Ridge, D. 2013. 'I was so done in that I just recognized it very plainly, You need to do something"': Men's narratives of struggle, distress and turning to meditation. Health: 17(2):191-208.

McCarthy, M. 2013. Antidepressant use has doubled in rich nations in past 10 years. British Medical Journal 347: f7261.

McInnes, I. 2014. Fight against rheumatoid arthritis may unlock secrets to heart disease and depression. The Australian Journal of Pharmacy 95(1129):12.

McMullen, L.M. and Sigurdson, K.J. 2014. Depression is to diabetes as antidepressants are to insulin: The unraveling of an analogy? Health Communication 29(3):309-17.

McPherson, S., and Armstrong, D. 2006. Social determinants of diagnostic labels in depression. Social Science \& Medicine 62(1):50-58.

—. 2009. Negotiating 'depression' in primary care: A qualitative study. Social Science \& Medicine 69(8):1137-43. 
Middleton, H., and Moncrieff, J. 2011. 'They won't do any harm and might do some good': Time to think again on the use of antidepressants? British Journal of General Practice 61(582):47-49.

Milton, J. 2001. Psychoanalysis ahd cognitive behavioural therapy - rival paradigms or common ground. The International Journal of Psychoanalysis 82(3):431-47.

Moncrieff, J. and Kirsch, I. 2005. Efficacy of antidepressants in adults. British Medical Journal 331(7509):155-57.

Morgan, J. 2017. If other ways don't work, try the immune system? The Lancet Neurology 16(2):109.

NICE. 2009. Depression in Adults: The treatment and management of depression in adults. in NICE clinical guideline 90: National Institute for Health and Clinical Excellence.

Pilgrim, D. 2007. The survival of psychiatric diagnosis. Social Science \& Medicine 65(3):536-47.

Pilgrim, D., Rogers, A. and Bentall, R. 2009. The centrality of personal relationships in the creation and amelioration of mental health problems: The current interdisciplinary case. Health 13(2):235-54.

Priebe, S., Burns, T. and Craig, T.K.J. 2013. The future of academic psychiatry may be social. The British Journal of Psychiatry 202(5):319-20.

Ridge, D. 2009. Recovery from Depression Using the Narrative Approach. London: Jessica Kingsley Publishers.

Ridge, D., Kokanovic, R., Broom, A., Kirkpatrick, S., Anderson, C. and Tanner, C. 2015. 'My dirty little habit': Patient constructions of antidepressant use and the 'crisis' of legitimacy. Social Science \& Medicine 146:53-61. 
Ridge, D., and Ziebland, S. 2006. 'The Old Me Could Never Have Done That': How People Give Meaning to Recovery Following Depression. Qualitative Health Research 16(8):1038-53.

—. 2012. Understanding depression through a 'coming out' framework. Sociology of Health \& IIIness 34(5):730-45.

Rizq, R. 2012. The perversion of care: Psychological therapies in a time of IAPT. Psychodynamic Practice 18(1):7-24.

Rogers, A., and Pilgrim, D. 2014. A Sociology of Mental Health and Illness. Maidenhead: Open University Press.

Ryan, A., and Wilson, S. 2008. Internet healthcare: Do self-diagnosis sites do more harm than good? Expert Opinion on Drug Safety 7(3):227-29.

Shariatmadari, D. 2015. What is depression? You asked Google - here's the answer. in The Guardian. London: The Guardian.

Shepherd, G., Boardman, J. and Slade, M. 2008. Making recovery a reality. London: Sainsbury Centre for Mental Health.

Spence, R., Roberts, A., Ariti, C. and Bardsley, M. 2014. Focus On: Antidepressant prescribing. London: Nuffield Trust.

Stern, M., and Brown, A. 2016. 'It's 5:30. I'm exhausted. And I have to go all the way to f*\%\#ing Fishtown.': Educator Depression, Activism, and Finding (Armed) Love in a Hopeless (Neoliberal) Place. The Urban Review 48(2):333-54.

Tamam, L. and Ozpoyraz, N. 2002. Selective serotonin reuptake inhibitor discontinuation syndrome: A review. Advances in Therapy 19(1):17-26.

Trivelli, E. 2014. Depression, performativity and the conflicted body: An autoethnography of self-medication. Subjectivity 7(2):151-70. 
Victora, C.G., Habicht, J.P. and Bryce, J. 2004. Evidence-Based Public Health: Moving Beyond Randomized Trials. American Journal of Public Health 94(3):400-05.

Wakefield, J.C., and First, M.B. 2012. Validity of the bereavement exclusion to major depression: does the empirical evidence support the proposal to eliminate the exclusion in DSM-5? World Psychiatry 11(1):3-10.

WHO. 2012. WHO Fact Sheet - Depression. Geneva: World Health Organisation. 